\title{
Material Properties and Compressibility Using Heckel and Kawakita Equation with Commonly Used Pharmaceutical Excipients
}

\author{
Du Hyung Choi, Nam Ah Kim, Kyung Rok Chu, Youn Jung Jung, \\ Jeong-Hyun Yoon and Seong Hoon Jeong ${ }^{\dagger}$ \\ College of Pharmacy, Pusan National University, Busan, 609-735, South Korea \\ (Received July 13, 2010 • Revised July 27, 2010 • Accepted July 28, 2010)
}

\begin{abstract}
This study investigated basic material properties and compressibility of commonly used pharmaceutical excipients. Five classes of excipients are selected including starch, lactose, calcium phosphate, microcrystalline cellulose (MCC), and povidone. The compressibility was evaluated using compression parameters derived from Heckel and Kawakita equation. The Heckel plot for lactose and dicalcium phosphate showed almost linear relationship. However, for MCC and povidone, curves in the initial phase of compression were observed followed by linear regions. The initial curve was considered as particle rearrangement and fragmentation and then plastic deformation at the later stages of the compression cycle. The Kawakita equation showed MCC exhibited higher compressibility, followed by povidone, lactose, and calcium phosphate. MCC undergoes significant plastic deformation during compression bringing an extremely large surface area into close contact and facilitating hydrogen bond formation between the plastically deformed, adjacent cellulose particles. Lactose compacts are consolidated by both plastic deformation and fragmentation, but to a larger extent by fragmentation. Calcium phosphate has poor binding properties because of its brittle nature. When formulating tablets, selection of suitable pharmaceutical excipients is very important and they need to have good compression properties with decent powder flowability. Material properties tested in this study might give a good guide how to select excipients for tablet formulations and help the formulation scientists design the optimum ones.
\end{abstract}

Key words - pharmaceutical excipients, Heckel plot, Kawakita equation, compressibility, material property

Pharmaceutical tablets have been the most frequently used method of drug administration due to their many advantages; they are easy to manufacture with well-developed scale up processes, convenient to administer with better patient compliance, and accurate for dosing. Tablets manufacturing looks simple, but rather be a complicated process with many pharmaceutical operations (Wu et al., 2005). The key point will be compression of powder formulations in a die, so both flowability and compressibility are critical properties. Other processes including mixing (dry or wet) and agglomeration and selection of process parameters applied to tablet equipments are also important factors. The compressed tablets are ejected out of the die and subjected to post-compaction operations. Disintegration and dissolution behaviors need to be within the tablets' expected properties and also mechanical integrity should be maintained during the shelf life.

Good tablets might be initiated from the selection of excipients for tablet formulations. Excipients need to have good binding properties on compression and decent powder flowability. Moreover, they should be compatible chemically and physically with an active pharmaceutical ingredient (API)

\footnotetext{
†Corresponding Author:

Tel : +82-51-510-2812, E-mail : shjeong@pusan.ac.kr

DOI : 10.4333/KPS.2010.40.4.237
}

and be able to incorporate high amount of the API. A welldesigned particle size distribution may give favorable mixing conditions. Therefore, better understanding of the physicochemical and material properties of the excipients is critical for their proper use and successful tablet preparation (Bolhuis, 1996; Yeli et al., 2003).

The compression process is a pharmaceutical unit process in which certain external mechanical force is applied to materials held in a die cavity through an upper and a lower punch. There are many events occurring in the process of compression; particle rearrangement, deformation at point of contact, fragmentation and/or deformation, bonding, deformation of the solid body, decompression, and ejection (Parrott, 1990). The onset of loading is normally accompanied by closer repacking of the particles or particle rearrangement, which will be the main mechanism of initial volume reduction. As the force increases, however, rearrangement becomes more difficult, and further compression causes some types of particle deformation including plastic/elastic deformation and fragmentation. On removal of the force, the deformation is to a large extent spontaneously reversible. If particles behave like a rubber, then the deformation is said to be elastic and all solids undergo some elastic deformation when subjected to external mechanical 
forces (Marshall, 1989)

The compaction behavior of pharmaceutical excipients may affect the quality and commercial viability of a tablet formulation. Among the many indices, compressibility and compactibility will be important; compressibility is the ability of the material to undergo volume reduction and compactibility is the ability of a material to yield a compact with adequate strength (Celik and Marshall, 1989). Compressibility may give basic information about the compression process, which is fundamental for the understanding of compactibility. The compressibility parameters of pharmaceutical excipients might be determined from the relationship between applied pressure and compact volume (Zhao et al., 2006).

There have been a number of compaction equations proposed to characterize the compression process. Equations such as Heckel, Kawakita, Walker and Bal'shin, and Cooper and Eaton are typical examples to investigate this relationship (Celik, 1992). However, many of the equations have been shown to have applicability over only a limited range of applied force and for a few types of materials. No universal relationship has yet developed and is unlikely to do so, since the comprehensive analysis of the mechanisms is difficult due to a complexity of the systems being compacted (Celik, 1992). However, the Heckel and the Kawakita equation have been used widely for relating a powder bed's relative density during the compression to the applied pressure. This study was designed to investigate the compressibility of commonly used pharmaceutical excipients and test the porosity-pressure relationship in an attempt to understand, characterize, and compare the binding functionality of the materials. Moreover, it might offer a selection guide when to choose excipients for tablet formulations.

\section{Materials and Methods}

\section{Materials}

The excipients evaluated in this study were purchased from commercial suppliers and used as received. MCC PH101 (microcrystalline cellulose, Heweten 101), MCC PH102 (microcrystalline cellulose, Heweten 102), Vivapur 12 (microcrystalline cellulose, average particle size $180 \mu \mathrm{m}$ ), Vivapur 101 (microcrystalline cellulose, average particle size $65 \mu \mathrm{m}$ ), Vivapur 102 (microcrystalline cellulose, average particle size $100 \mu \mathrm{m}$ ), Vivapur 105 (microcrystalline cellulose, average particle size $25 \mu \mathrm{m}$ ), and Vivapress (precipitated calcium carbonate, calcium content $>39.4 \%$ ) were obtained from JRS Pharma (Patterson, NY, USA). Starch $1500^{\circledR}$ is a pregelatinized starch and obtained from Colorcon (Indianapolis, IN, USA).
SuperTab $^{\circledR} 21 \mathrm{AN}$ is anhydrous lactose and obtained from DMV International (Veghel, Netherlands). SuperTab ${ }^{\circledR} 11$ SD and 14SD are spray dried lactose monohydrate and obtained also from DMV International. Di-Tab is a dicalcium phosphate dihydrate and obtained from Innophos (Cranbury, NJ, USA). Tablettose ${ }^{\circledR} 80$ is an agglomerated alpha lactose monohydrate, Granulac $^{\circledR} 230$ is a lactose monohydrate, and FlowLac ${ }^{\circledR} 100$ is a spray dried alpha-lactose monohydrate. They were obtained from Meggle Pharma (Molkerei Meggle Wasserburg GmbH \& Co. KG, Germany).

\section{Particle Size Analysis}

Particle size and size distribution for all samples were measured by Sympatec HELOS (Sympatec GmbH, ClausthalZellerfeld, Germany). Approximately $1.0 \mathrm{~g}$ of powder was used for each measurement. The air pressure was set at 1.0 bar. Mass median particle diameter, particle diameter that divides the frequency distribution in half $(50 \%$ of the mass has particles with a larger diameter, and $50 \%$ of the mass has particles with a smaller diameter) and the particle size distribution were recorded. Each sample was measured in triplicate.

\section{Density Measurement}

The true density of each excipient was determined by a helium pycnometer (AccuPyc 1330, Micromeritics Instrument Corp., Norcross, GA, USA). The accuracy of the pycnometer was checked using a standard steel sphere before measurements on a series of samples. The experimental sample was accurately weighed and loaded into the sample cell. The sample volume was computed by measurements of the pressure observed by filling the sample chamber with ultra-high pure helium gas followed by discharging the gas into a second empty chamber. The measurements were repeated for 5 cycles.

The bulk and tap density of the excipients was determined by MT-1000 (Seishin Enterprise Co., Tokyo, Japan). Bulk density was determined after dropping powder at $100 \mathrm{~mL}$ mass cylinder for MT-1000. Tab density was determined after 2000 taps. Each analysis was repeated three times.

The increase in bulk of a powder is related to the cohesivity of a powder. Ratios of the poured to tapped bulk densities are expressed in two ways to give indices of flowability.

Hausner Ratio $=\frac{\text { tapped bulk density }}{\text { poured bulk denstiy }}$

Compressibility $($ Carr Index $)=$

$\frac{100 \times(\text { tapped bulk density }- \text { poured bulk denstiy }}{\text { poured bulk density }}$ 
The Hausner ratio varies from about 1.2 for a free-flowing powder to 1.6 for cohesive powders. The Carr Index classifications are listed in 5-12\% (free flowing), 12-16\% (good flow), $18-21 \%$ (fair flow), 23-35\% (poor flow), 33-38\% (very poor flow), and above $40 \%$ (extremely poor) (Davies, 2004).

\section{Angle of Repose}

The angle of repose was determined by the MT-1000. Each excipient is poured from a funnel onto a horizontal surface and it forms a cone. The angle between the sides of the cone and the horizontal is referred to as the angle of repose. Each analysis was repeated three times. This method might be simple in concept, but not particularly discerning. However, it can give a rough guide when to evaluate excipients. Powders with angles less than $30^{\circ}$ are usually an indicative of good flow, while angles greater than $40^{\circ}$ may induce issues in powder flow and also in manufacturing process.

\section{Tablet Preparation}

Tablets of $500 \mathrm{mg}$ were compressed on a single punch Carver Laboratory Press (Carver Inc., Wabash, IN, USA) at different compression pressures using plane-face punches with a diameter of $12 \mathrm{~mm}$. Fifteen different compaction forces (from $20 \mathrm{MPa}$ to $400 \mathrm{MPa}$ ) were used for each material. Each compact was weighed accurately, and its dimensions were measured with a digital slide caliper (Mitutoyo Co., Kawasaki, Japan) $(\mathrm{n}=5)$.

\section{Tablet Hardness}

Crushing strength of a compact was determined by compressing a compact diametrically on an Erweka tablet tester (Erweka TBH 225TD, Heusenstamm, Germany). The radial tensile strength of the compacts was calculated from the compact crushing strength and compact thickness in accordance with Fell and Newton's method (Fell and Newton, 1968; Habib et al., 1996), in which the radial tensile strength $\sigma x$ is given by;

$$
\sigma_{x}=\frac{2 x}{\pi d t}
$$

where $\sigma_{x}$ is the tensile strength (MPa), $x$ is the force required to cause failure in tension $(\mathrm{N}), d$ is the diameter of the compact $(\mathrm{mm})$, and $t$ is the thickness of the compact (mm). The use of tensile strength allows the dimensions of the compact to be taken into account, which is in contrast to the use of crushing strength. Only the force that led to sample failure in tension was used for the calculation of tensile strength.

\section{Heckel Analysis}

The most commonly used equation in the pharmaceutical compaction studies was developed by Heckel (Heckel, $1961 \mathrm{a}, \mathrm{b})$. It is based on the assumption that powder compression follows first-order kinetics, with the interparticulate pores as the reactant and the densification of the powder bed as the product. The Heckel equation is described as following;

$$
\ln \frac{1}{1-D}=k P+A
$$

where $D$ is the relative density of a powder compact at pressure $P$. Constant $k$ is a measure of the plasticity of a compressed material. Constant $A$ is related to the die filling and particle rearrangement before deformation and bonding of the discrete particles. The Heckel plot for the compaction of pharmaceutical powders allows an interpretation of the consolidation mechanisms and a measure of the yield pressure of the powders.

\section{Kawakita Analysis}

Another equation representing the relation between the pressure and the volume of powdered mass under compression was introduced earlier and the compaction behavior can be analyzed by Kawakita equation (Nicklasson and Alderborn, 2000; Kawakita et al., 1998; Kawakita, 1956; Yamashiro et al., 1983)

$$
\begin{aligned}
& C=\frac{\left(V_{0}-V\right)}{V_{0}}=\frac{a b P}{1+b p} \\
& \frac{P}{C}=\frac{P}{a}+\frac{1}{a b}
\end{aligned}
$$

where $C$ is the relative reduction in volume by the compression. $V_{0}$ is the initial apparent volume and $V$ is the volume of the particle under the applied pressure $P$. A plot of $P / C$ against $P$ can give a straight line for deriving $a$. The constant $a$ corresponds to the limiting value of the relative reduction of the volume by compression and is equal to the value of the initial porosity. The constant $b$ is inversely related to the yield strength of the particles and has the dimension of the reciprocal of stress.

\section{Results and Discussion}

Table I shows the particle size of the pharmaceutical excipients measured in this study. $\mathrm{X}_{10}, \mathrm{X}_{50}$, and $\mathrm{X}_{90}$ are $10 \%, 50 \%$, and $90 \%$ cumulative distribution values, respectively. It shows wide range of particle size and size distribution. The smallest ones are Vivapur 105 and GranuLac 230, around $22 \mu \mathrm{m}\left(\mathrm{X}_{50}\right)$. The biggest one reaches up to $200 \mu \mathrm{m}$. All the materials are 
Table I. Particle Size of Commercially Available Pharmaceutical Excipients Tested in this Study

\begin{tabular}{lrrr}
\hline \multicolumn{1}{c}{ Excipient } & $\mathrm{X}_{10}(\mu \mathrm{m})$ & $\mathrm{X}_{50}(\mu \mathrm{m})$ & $\mathrm{X}_{90}(\mu \mathrm{m})$ \\
\hline Starch 1500 & 13.67 & 60.83 & 145.00 \\
Vivapur 12 & 49.21 & 161.68 & 298.27 \\
Vivapur 101 & 22.08 & 60.03 & 123.55 \\
Vivapur 102 & 27.76 & 100.42 & 217.40 \\
Vivapur 105 & 8.67 & 22.94 & 55.28 \\
MCC 101 & 23.25 & 66.30 & 130.30 \\
MCC 102 & 26.45 & 94.48 & 211.78 \\
Ludipress & 83.11 & 206.93 & 337.23 \\
Tablettose 80 & 49.07 & 162.75 & 334.17 \\
FlowLac 100 & 49.05 & 137.71 & 231.07 \\
SuperTab 11SD & 42.92 & 108.39 & 203.26 \\
SuperTab 14SD & 37.34 & 103.84 & 203.83 \\
SuperTab 21AN & 10.57 & 147.62 & 334.17 \\
GranuLac 230 & 4.09 & 22.28 & 70.11 \\
Cellactose 80 & 51.03 & 163.90 & 273.28 \\
PVP K30 & 31.95 & 88.40 & 155.40 \\
PVP K90 & 68.01 & 150.88 & 262.51 \\
Di-Tab & 45.84 & 143.93 & 243.98 \\
\hline
\end{tabular}

within the specifications of the manufacturers'.

The bulk, tapped, and true densities for the tested excipients are measured and listed in Table II. True density seems to be dependent on the chemical components of the excipients. Calcium carbonate (Vivapress) and dicalcium phosphate (Di-Tab) show higher true densities with relatively higher bulk and tapped densities. Regarding the true density, lactose comes after the calcium phosphate followed by starch, MCC, and povidone. Even though the difference may not be significant, particle size may affect the bulk density as shown in the Vivapur series (Table II). As the mean particle size increased from 23 to $160 \mu \mathrm{m}$, the bulk density also increased from 0.24 to $0.32 \mathrm{~g} / \mathrm{mL}$. It might be due to the increased interparticle repulsion forming a 'fluffy state' as the particle size decreased, which might make more void space. However, the interparticle interaction was compromised by the tapping as shown in the Vivapur series (Table II). On the other hand, different trends can be observed in MCC. Therefore, powders' overall properties need to be investigated carefully when to formulate tablet dosage forms.

The flowability can be evaluated using powder properties such as density, surface area, moisture content, particle shape, particle size, and size distribution. Among the many methods available, Carr index and angle of repose have been used widely to get a rough idea on the flow properties. Generally, directly compressible materials may have good flowability due to their additional manufacturing process for the improvement of powder properties like spray drying, spheronization, for-

Table II. Densities, Carr Index, and Angle of Repose for Commonly Used Commercially Available Pharmaceutical Excipients

\begin{tabular}{|c|c|c|c|c|c|c|c|c|c|c|c|c|c|c|c|}
\hline \multirow{3}{*}{$\begin{array}{l}\text { Excipients } \\
\text { Starch } 1500\end{array}$} & \multicolumn{9}{|c|}{ Density $(\mathrm{g} / \mathrm{mL})$} & \multirow{2}{*}{\multicolumn{3}{|c|}{ Carr index }} & \multirow{2}{*}{\multicolumn{3}{|c|}{ Angle of repose $\left(^{\circ}\right)$}} \\
\hline & \multicolumn{3}{|c|}{ Bulk } & \multicolumn{3}{|c|}{ Tapped } & \multicolumn{3}{|c|}{ True } & & & & & & \\
\hline & 0.49 & \pm & 0.00 & 0.72 & \pm & 0.00 & 1.50 & \pm & 0.00 & 31.60 & \pm & 0.00 & 42.47 & \pm & 0.38 \\
\hline Vivapur 12 & 0.32 & \pm & 0.00 & 0.46 & \pm & 0.00 & 1.55 & \pm & 0.00 & 30.20 & \pm & 0.45 & 37.20 & \pm & 1.02 \\
\hline Vivapur 101 & 0.29 & \pm & 0.01 & 0.47 & \pm & 0.00 & 1.56 & \pm & 0.00 & 39.00 & \pm & 0.00 & 43.89 & \pm & 0.19 \\
\hline Vivapur 102 & 0.30 & \pm & 0.01 & 0.48 & \pm & 0.00 & 1.56 & \pm & 0.00 & 36.67 & \pm & 0.00 & 43.22 & \pm & 0.39 \\
\hline Vivapur 105 & 0.24 & \pm & 0.01 & 0.47 & \pm & 0.00 & 1.56 & \pm & 0.00 & 50.00 & \pm & 0.00 & 44.78 & \pm & 0.19 \\
\hline MCC 101 & 0.28 & \pm & 0.00 & 0.46 & \pm & 0.00 & 1.59 & \pm & 0.00 & 39.33 & \pm & 0.00 & 42.67 & \pm & 0.88 \\
\hline MCC 102 & 0.32 & \pm & 0.00 & 0.51 & \pm & 0.00 & 1.57 & \pm & 0.00 & 37.67 & \pm & 0.00 & 43.22 & \pm & 0.84 \\
\hline Ludipress & 0.52 & \pm & 0.00 & 0.63 & \pm & 0.00 & 1.49 & \pm & 0.00 & 18.00 & \pm & 0.71 & 34.93 & \pm & 0.64 \\
\hline Tablettose 80 & 0.51 & \pm & 0.00 & 0.67 & \pm & 0.00 & 1.54 & \pm & 0.00 & 23.60 & \pm & 0.00 & 45.40 & \pm & 0.28 \\
\hline FlowLac 100 & 0.51 & \pm & 0.00 & 0.64 & \pm & 0.00 & 1.54 & \pm & 0.00 & 20.60 & \pm & 0.00 & 39.47 & \pm & 0.45 \\
\hline SuperTab1 1SD & 0.61 & \pm & 0.00 & 0.75 & \pm & 0.00 & 1.54 & \pm & 0.00 & 19.00 & \pm & 0.00 & 35.56 & \pm & 0.51 \\
\hline SuperTab14SD & 0.63 & \pm & 0.01 & 0.76 & \pm & 0.01 & 1.54 & \pm & 0.00 & 17.67 & \pm & 0.00 & 34.67 & \pm & 0.33 \\
\hline SuperTab21AN & 0.66 & \pm & 0.00 & 0.97 & \pm & 0.00 & 1.58 & \pm & 0.00 & 31.66 & \pm & 0.00 & 45.44 & \pm & 0.39 \\
\hline GranuLac 230 & 0.30 & \pm & 0.02 & 0.80 & \pm & 0.01 & 1.53 & \pm & 0.00 & 62.67 & \pm & 0.00 & 48.89 & \pm & 2.12 \\
\hline Cellactose 80 & 0.49 & \pm & 0.00 & 0.63 & \pm & 0.01 & 1.56 & \pm & 0.00 & 22.00 & \pm & 0.00 & 37.11 & \pm & 0.19 \\
\hline PVP K30 & 0.41 & \pm & 0.01 & 0.51 & \pm & 0.00 & 1.22 & \pm & 0.00 & 21.33 & \pm & 0.00 & 40.11 & \pm & 0.19 \\
\hline PVP K90 & 0.40 & \pm & 0.00 & 0.55 & \pm & 0.00 & 1.21 & \pm & 0.00 & 26.33 & \pm & 0.00 & 37.11 & \pm & 0.19 \\
\hline Di-Tab & 0.83 & \pm & 0.00 & 1.05 & \pm & 0.00 & 2.43 & \pm & 0.00 & 21.33 & \pm & 0.00 & 36.56 & \pm & 0.19 \\
\hline Vivapress & 0.91 & \pm & 0.00 & 1.07 & \pm & 0.00 & 2.58 & \pm & 0.00 & 15.00 & \pm & 0.0 & 44.80 & \pm & 0.30 \\
\hline
\end{tabular}


mation of aggregation, and so on. Among the tested excipients, Vivapress, SuperTab 14SD, and Ludipress showed good flowability based on the Carr index (less than 20). Because of bigger particle size, Vivapur 12 showed better flow properties than the other Vivapurs, MCC 101, and MCC 102. Moreover, the particle shape of the excipient is more spherical than the other two MCC excipients. Vivapur 105 showed poor flowability with the Carr index of 50. Its particle size is very small $\left(\mathrm{X}_{50}=22.94 \mu \mathrm{m}\right)$ and also formed low bulk density, which may support the poor flowability. SuperTab SD showed better flow properties than SuperTab AN because of its spherical shape and a narrow particle size distribution. GranuLac 230 exhibited very poor flow properties among the tested lactose and it showed small particle size $\left(\mathrm{X}_{50}=22.28 \mu \mathrm{m}\right)$, high Carr index (about 62.67), and high angle of repose (about $48.89^{\circ}$ ).

While the Heckel plot is simple to use, it may give valuable guide when to choose relevant excipients especially for tablet formulation. The two equation constants of the Heckel plot for the excipients are shown in Table III. The constants are commonly determined by the linear regression analysis by using the least-squares method. However, some difficulties are associated with this procedure. Correct selection of a linear region of the function is very important and thus the coefficient of determination value greater than 0.95 was mainly selected. Applied pressure was from 23.25 $\mathrm{MPa}$ to $154.99 \mathrm{MPa}$. The
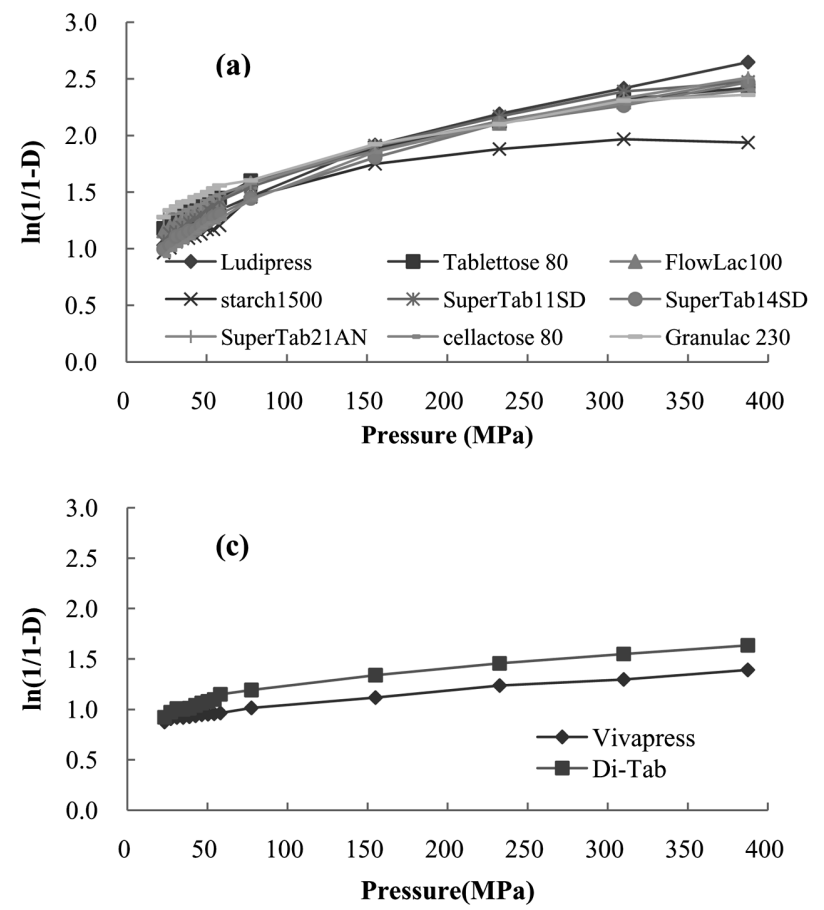

Table III. Heckel Plot Constants for Commonly Used Commercially Available Pharmaceutical Excipients

\begin{tabular}{llcc}
\hline \hline \multicolumn{1}{c}{ Excipient } & $k(1 / \mathrm{MPa})$ & $A$ & $r^{2}$ \\
\hline Starch 1500 & $0.30 \times 10^{-2}$ & 1.02 & 0.87 \\
Vivapur 12 & $0.82 \times 10^{-2}$ & 0.73 & 0.95 \\
Vivapur 101 & $0.85 \times 10^{-2}$ & 0.73 & 0.96 \\
Vivapur 102 & $0.82 \times 10^{-2}$ & 0.73 & 0.95 \\
Vivapur 105 & $0.84 \times 10^{-2}$ & 0.77 & 0.96 \\
MCC 101 & $0.78 \times 10^{-2}$ & 0.81 & 0.93 \\
MCC 102 & $0.87 \times 10^{-2}$ & 0.74 & 0.95 \\
Ludipress & $0.65 \times 10^{-2}$ & 1.03 & 0.99 \\
Tablettose 80 & $0.35 \times 10^{-2}$ & 1.22 & 0.96 \\
FlowLac 100 & $0.37 \times 10^{-2}$ & 1.17 & 0.97 \\
SuperTab 11SD & $0.40 \times 10^{-2}$ & 1.11 & 0.95 \\
SuperTab 14SD & $0.41 \times 10^{-2}$ & 1.02 & 0.97 \\
SuperTab 21AN & $0.35 \times 10^{-2}$ & 1.24 & 0.98 \\
GranuLac 230 & $0.30 \times 10^{-2}$ & 1.33 & 0.96 \\
Cellactose 80 & $0.42 \times 10^{-2}$ & 0.98 & 0.95 \\
PVP K30 & $0.85 \times 10^{-2}$ & 0.61 & 0.98 \\
PVP K90 & $0.75 \times 10^{-2}$ & 0.59 & 0.95 \\
Di-Tab & $0.30 \times 10^{-2}$ & 0.91 & 0.91 \\
Vivapress & $0.17 \times 10^{-2}$ & 0.86 & 0.97 \\
\hline
\end{tabular}

slope of the Heckel plot $(k)$ is indicative of the plastic behavior of the materials and a larger value for the slope is related to a
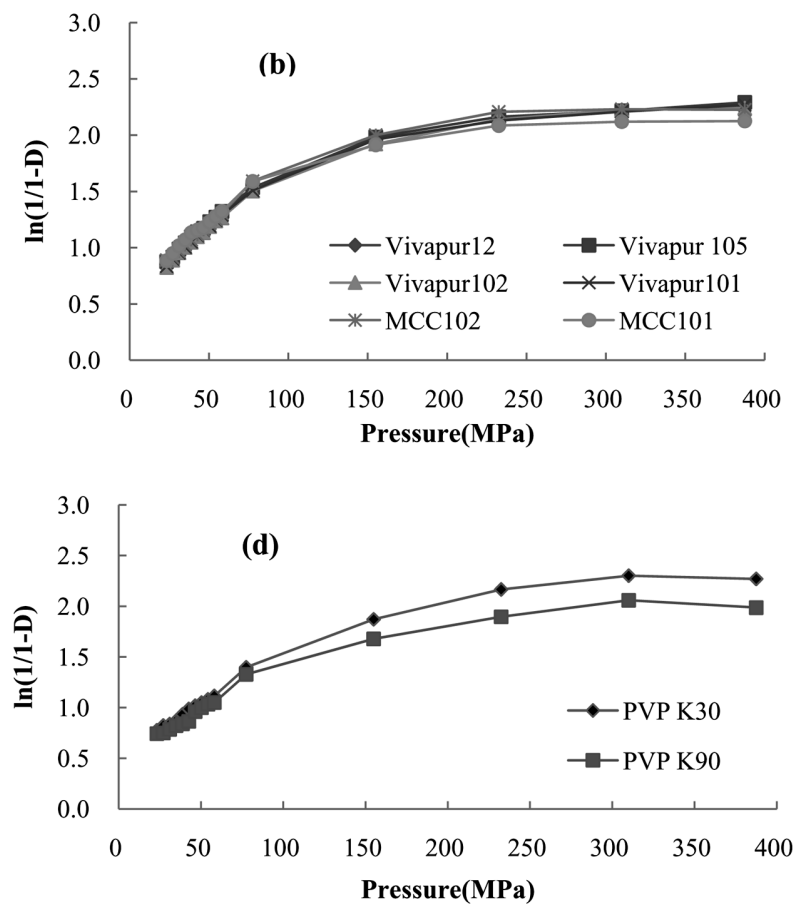

Figure 1. Heckel plots of the various pharmaceutical excipients tested in the study; (a) lactose series, (b) MCC series, (c) dicalcium phosphate, and (d) povidones. 
higher plasticity of the material. The plasticity decreases in the following order: MCC, lactose and starch, and calcium phosphate. Comparatively, soft materials often have high linearity and they undergo mainly plastic deformation while retaining different degrees of porosity depending on the initial packing arrangement in the die. During the initial phase of compression cycle, it shows a curve at low compression pressures, which indicates particle rearrangement and fragmentation. As compression progresses, the higher linearity obtained indicates that mainly plastic deformation is taking place.

The Heckel plots for lactose and dicalcium phosphate showed almost linear relationships (Figure 1). Different particle size fractions had different initial packing and the plots remained parallel as the compression pressure increased. The Heckel plots for MCC and povidone showed curves in the initial phase of compression, followed by linear regions. The initial curve was considered that particle rearrangement and fragmentation were occurring during the initial stages and then plastic deformation at the later stages of the compression cycle.

The Kawakita constants, $a$ and $b$ for each of the excipients evaluated are listed in Table IV. In considering of $a$ parameter, MCC series especially Vivapur 105 exhibited the highest compressibility, followed by povidone, lactose, and calcium phosphate. In considering of $b$ constant, MCC series including Vivapur 105 showed the lowest yield strength, followed by lactose and povidone. The classes of calcium phosphate, starch, and povidone showed relatively high yield strength.

Results of the radial tensile strength are shown in Figure 2. It showed that as the compression force increased, tensile strength also increased. At the same compression force, MCC produced harder compacts, whereas calcium phosphate formed soft ones. On the other hand, compacts made of Ludipress and starch 1500 exhibited similar tensile strength to calcium phosphate. In general, MCC materials showed excellent compact hardness. According to the Bolhuis, Lee, and Tsai (Bolhuis, 1996; Lee et al., 2000; Tsai et al., 1998), hydrogen bonding played an important role in compact hardness. For MCC excipients, they undergo significant plastic deformation during compression bringing a significantly large surface area into contact and facilitating hydrogen bond formation between the plastically deformed, adjacent cellulose particles. Additionally, moisture within the porous structure of MCC may act as an internal lubricant. This can facilitate slippage and flow within the individual particles during plastic deformation, which forms strong hydrogen bond bridges and gives MCC a strong compact.
Table IV. Kawakita Constants of the Commercially Available Pharmaceutical Excipients Tested in this Study

\begin{tabular}{lccc}
\hline \hline \multicolumn{1}{c}{ Excipient } & $a$ & $b$ & $r^{2}$ \\
\hline Starch 1500 & 0.63 & 23.84 & 1.00 \\
Vivapur 12 & 0.79 & 8.84 & 1.00 \\
Vivapur 101 & 0.81 & 6.97 & 1.00 \\
Vivaspur 102 & 0.79 & 7.98 & 1.00 \\
Vivapur 105 & 0.84 & 4.62 & 1.00 \\
MCC 101 & 0.81 & 5.43 & 1.00 \\
MCC 102 & 0.78 & 8.08 & 1.00 \\
Ludipress & 0.58 & 18.48 & 1.00 \\
Tablettose 80 & 0.64 & 17.14 & 1.00 \\
FlowLac 100 & 0.65 & 18.59 & 1.00 \\
SuperTab 11SD & 0.58 & 37.58 & 1.00 \\
SuperTab 14SD & 0.58 & 50.23 & 1.00 \\
SuperTab 21AN & 0.56 & 35.97 & 1.00 \\
GranuLac 230 & 0.79 & 3.97 & 1.00 \\
Cellactose 80 & 0.67 & 22.94 & 1.00 \\
PVP K30 & 0.66 & 39.06 & 1.00 \\
PVP K90 & 0.65 & 45.22 & 1.00 \\
Di-Tab & 0.59 & 29.62 & 1.00 \\
Vivapress & 0.44 & 11.98 & 1.00 \\
\hline
\end{tabular}

Lactose produced soft compacts as shown in the Figure 2. Lactose compacts are known to be consolidated by plastic deformation and fragmentation, but mainly by fragmentation (van der Voort Maarschalk and Bolhuis, 1998a,b; Cole et al., 1975). Fragmentation makes a large number of smaller particles so the number of contact points that support the applied load is large. Therefore, the stress on each contact point is relatively small and the bond strength formed in compacts might be relatively low. Calcium phosphate has poor binding properties. Due to the brittle nature of the material, it undergoes considerable fragmentation during compression. Similarly, fracture creates a large number of interparticulate contact points with a relatively weak bonding so the compact strength might be low.

When external mechanical forces are applied to a powder mass, bulk volume will be reduced by the following mechanisms. The onset of loading is usually accompanied by particle rearrangement (closer repacking of particles) causing initial volume reduction. As the load increases, the rearrangement becomes more difficult and further compression induces some types of particle deformation. On removal of the load, the deformation is reversible to a large extent. If it 

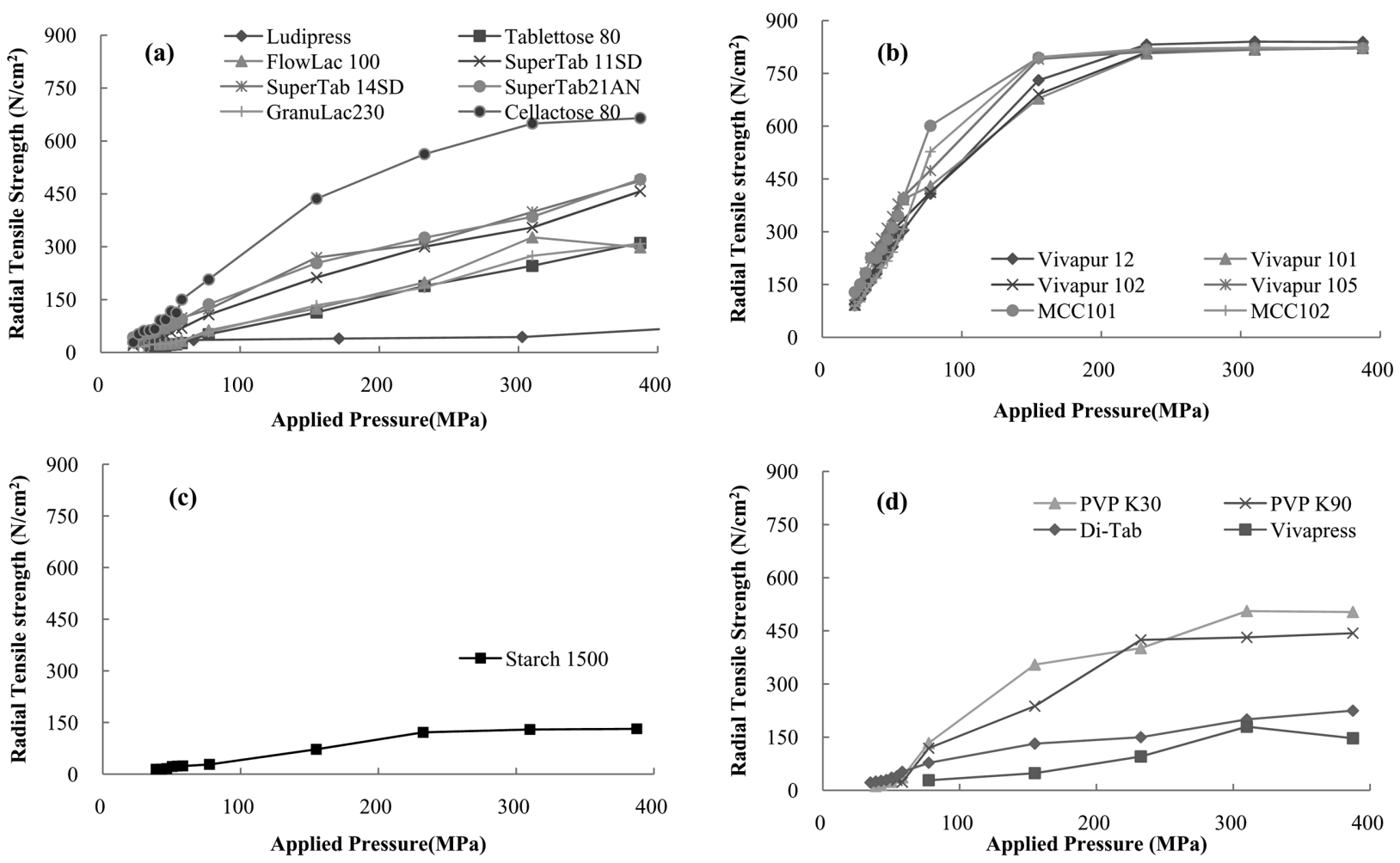

Figure 2. Radial tensile strength of the commercially available pharmaceutical excipients tested in the study; (a) lactose series, (b) MCC series, (c) starch, and (d) povidone and dicalcium phosphate.

behaves like a rubber, the deformation is regarded as elastic. All solid materials undergo elastic deformation when subjected to external forces. With several pharmaceutical materials like $\mathrm{MCC}$, elastic deformation becomes the dominant mechanism of compression within the range of maximum forces normally encountered in practice. When an elastic limit or yield point is reached, the further compression level results in deformation, which is not immediately reversible on removal of the applied force. This type of bulk volume reduction is said as plastic deformation and/or viscous flow of the particles in which particles are squeezed into the remaining void spaces. This mechanism is dominant in such materials when the shear strength is less than the tensile or breaking strength. Conversely, when the shear strength is greater, particles may be preferentially fractured and this is most likely to happen as brittle fracture.

Developing tablet dosage forms requires extensive study on the material properties together with physicochemical interactions between APIs and excipients. Physical properties such as densities, flowability, and compressibility have to be considered carefully when to design tablet formulations. It may look like time-consuming and not critical for the product development. However, it will make the development process shorten especially when they meet some formulation issues during the process.

\section{Conclusions}

This study provides basic materials properties and mechanical characteristics of commonly used pharmaceutical excipients and it may give a rough guide how to choose suitable excipients for the development of tablet formulations. Among the various materials, MCC undergoes significant plastic deformation during compression bringing an extremely large surface area into close contact and facilitating hydrogen bond formation between the plastically deformed, adjacent cellulose particles. Lactose compacts are consolidated by both plastic deformation and fragmentation, but to a larger extent by fragmentation. Calcium phosphate has poor binding properties because of its brittle nature. It undergoes considerable fragmentation during compression. There are a lot of excipients for the tablet formulation in the market and it will be formulation scientists' responsibility what to choose and how to formulate them. Material and mechanical properties as shown in this study might give a valuable guide for that purpose and help the scientists design the optimum formulations.

\section{Acknowledgements}

This work was supported for two years by Pusan National 
University Research Grant.

\section{References}

Bolhuis, G.K., 1996. Materials for direct compaction. In: Pharmaceutical Powder Compaction Technology. Marcel Dekker, New York, NY, USA, pp. 419-478.

Celik, M., 1992. Overview of compaction data analysis techniques, Drug Dev. Ind. Pharm. 18, 767-810.

Celik, M., Marshall, K., 1989. Use of a compaction simulator system in tableting research. Part 1.Introduction to and experiments with the system. Drug Dev. Ind. Pharm. 15, 759-800.

Cole, E.T., Rees, J.E., Hersey, J.A., 1975. Relations between compaction data for some crystalline pharmaceutical materials. Pharm. Acta. Helv. 50, 28-32.

Davies, P., 2004. Oral solid dosage forms, Pharmaceutical preformulation and formulation, Interpharm/CRC, Florida, USA, pp. $386-388$.

Fell, J.T., Newton, J.M., 1968. The tensile strength of lactose tablets. J. Pharm. Pharmacol. 20, 657-758.

Habib, Y., Ausburger, L., Reier, G., Wheatley, T., Shangraw, R., 1996. Dilution potential: a new perspective. Pharm. Dev. Technol. 1, 205-212.

Heckel, R.W., 1961a. An analysis of powder compaction behavior. Trans. Metallurgical Society, AIME. 221, 1001-1008.

Heckel, R.W., 1961b. Density-pressure relationships in powder compaction. Trans. Metallurgical Society, AIME. 221, 671675.

Kawakita, K., Hattori, I., Kishigami, M., 1998. Characteristics constants in Kawakita's compression equations. J.Powder Bulk Slids. Techn. 1, 3-8.

Kawakita, K., 1956. An empirical equation of state for powder compression, Science Japan 26, 149.

Lee, Y.S.L., Poynter, R., Podczeck, F., Newton, J.M., 2000. Development of a dual approach to assess powder flow from ava- lanching behavior. AAPS PharmSciTech. 1, Article 21.

Marshall, K., 1989. Compression and consolidation of powdered solids. In: The Theory and practice of Industrial Pharmacy. Lea and Febiger, Philadelphia, USA 66-100.

Nicklasson, F., Alderborn, G., 2000. Analysis of the compression mechanics of pharmaceutical agglomerates of different porosity and composition using the Adams and Kawakita equations. Pharm. Res. 17, 949-954.

Parrott, E.L., 1990. Compression. In: Pharmaceutical Dosage Forms: Tablets. Vol. 2, Marcel Dekker, New York, NY 153182.

Tsai, T., Wu, J.S., Ho, H.O., Sheu, M.T., 1998. Modification of physical characteristics of microcrystalline cellulose by codrying with $\beta$-cyclodextrins. J. Pharm. Sci. 87, 117-122.

van der Voort Maarschalk, K., Bolhuis, G.K., 1998a. Improving properties of materials for direct compression. Pharm. Technol. Europe 10, 30-35.

van der Voort Maarschalk, K., Bolhuis, G.K., 1998b. Improving properties of materials for direct compression. Pharm. Technol. Europe 10, 28-36.

Wu, C.Y., Ruddy, O.M., Bentham, A.C., Hancock, B.C., Best, S.M., Elliott, J.A., 2005. Modelling the mechanical behavior of pharmaceutical powders during compaction. Powder Technol. 152, 107-117.

Yamashiro, M., Yussa, Y., Kawakita, K., 1983. An experimental study on the relationships between compressibility, fluidity and cohesion of powder solids at small tapping numbers. Powder Technol. 34, 225.

Yeli, Z., Yuet, L., Sibu, C., 2003. Physical properties and compact analysis of commonly used direct compression binders. AAPS PharmSciTech. 4, Article 62.

Zhao, J., Burt, H.M., Miller, R.A., 2006. The Gurnham equation in characterizing the compressibility of pharmaceutical materials. Int. J. Pharm. 317, 109-113. 